\title{
Enhancements of the Critical Currents of YBaCuO Single Crystals by Neutron (n) and Proton (p) Irradiation*
}

\section{B.M. Vlcek, M.C. Frischherz, H.K. Viswanathan, U. Welp,}

\author{
G.W. Crabtree, and M.A. Kirk \\ Materials Science Division and Science \& Technology Center for Superconductivity
}

Argonne National Laboratory, Argonne, IL 60439

ANL/MSD/CP--78800

\begin{tabular}{|c|}
\hline $\begin{array}{l}\text { The submitted manuscript has been authored by } \\
\text { a contractor of the U.S. Government under } \\
\text { contrad No. W-31-100-ENG-38. Accordingly. } \\
\text { the U.S. Government retains a nonexelusive. } \\
\text { royaliy-tree Hoense to publish or reproduce the } \\
\text { published form of this contribution, of allow } \\
\text { others to do so, for U.S. Covernment purposes. }\end{array}$ \\
\hline
\end{tabular}

DE93 007892

\section{Applied Superconductivity Conference, Chicago, IL August 22-28, 1992}

jmc

\section{DISCLAIMER}

This report was prepared as an account of work sponsored by an agency of the United States Government. Neither the United States Government nor any agency thereof, nor any of their employees, makes any warranty, express or implied, or assumes any legal liability or responsibility for the accuracy, completeness, or usefulness of any information, apparatus, product, or process disclosed, or represents that its use would not infringe privately owned rights. Reference herein to any specific commercial product, process, or service by trade name, trademark, manufacturer, or otherwise does not necessarily constitute wr imply its endorsement, recommendation, or favoring by the United States Government or any agency thereof. The views and opinions of authors expressed herein do not necessarily state or reflect those of the United States Government or any agency thereof.
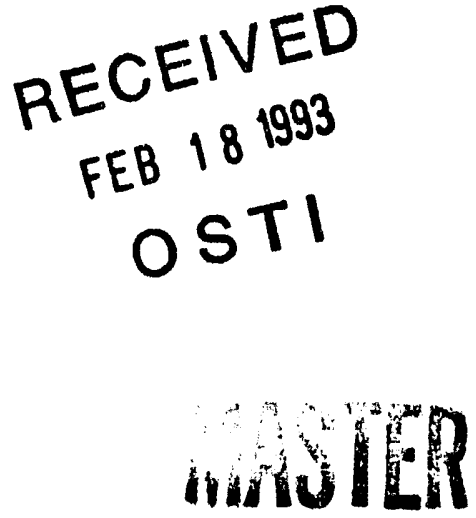

\footnotetext{
*Work supported in by the U.S. Department of Energy, BES-Materials Sciences under coi ract \#W-31-109-ENG-38 and the National Science Foundation-Office of Science and Technology Centers for Superconductvity under contract \#91-20000 (UW).
} 


\title{
ENHANCEMENTS OF THE CRITICAL CURRENTS OF YBaCUO SINGLE CRYSTALS BY NEUTRON (n) AND PROTON (p) IRRADIATION
}

\author{
B. M. Vlcek, M. C. Frischherz, H. K. Vishwanathan, U. Welp, G. W. Crabtree, M. A. Kirk \\ Material Science Division, Argonne National Laboratory, Il 60439
}

\begin{abstract}
We present the results of magnetization hysteresis and $T_{c}$ measurements of neutron and proton irradiated $\mathrm{YBaCuO}$ single crystals. The crystals used for comparison were irradiated to a fluence of $2 \times 10^{17} \mathrm{n} / \mathrm{cm}^{2}(\mathrm{n}, \mathrm{E}>0.1 \mathrm{MeV})$ and $1 \times 10^{16} \mathrm{p} / \mathrm{cm}^{2}(\mathrm{p}, \mathrm{E}=3.5 \mathrm{MeV})$. The critical currents at $1 \mathrm{~T}$ and $10 \mathrm{~K}$ are enhanced by a factor of 5 for the neutron irradiated and a factor of 9 for the proton irradiated sample respectively. After irradiation the crystals were annealed at 100,200 and $300^{\circ} \mathrm{C}$ for $8 \mathrm{~h}$ each in air. Following each annealing step the critical temperature and the magnetization hysteresis at 10 and $70 \mathrm{~K}$ was measured. Upon annealing, we observe a decrease of the critical currents, which is more pronounced for the proton irradiated sample. This decrease is related to thit removal of point defects or their small clusters. Thus, their contribution to pinning can be studied. The critical temperature decreases after both types of irradiation by about $0.5 \mathrm{~K}$ and is fully recovered after annealing.
\end{abstract}

\section{INTRODUCTION}

It is well established that the critical currents of $\mathrm{YBaCuO}$ single crystals increase upon irradiation with neutrons[1], protons [2], electrons [3]. The defects created are different depending on the kind of irradiation imposed on the material. Whereas with electron irradiation only point defects and point defect clusters are created, neutron and proton irradiation creates point defects, point defect clusters and cascade defects. Since proton irradiation possesses a larger fraction of low energy recoils than neutron irradiation at the chosen fluences [4], more point defects and less defect cascades compared to neutron irradiation are created. In earlier work, [5] it has been shown, that cascade defects are effective pinning centers. The role of point defects, in contrast has not yet been fully clarified, partly because they are invisible in conventional TEM. It has been shown in the study of electron irradiated crystals, that point defects are effective pinning centers [3], [6], and that they are removed by annealing [7]. Cascade defects, in contrast are stable at annealing temperatures up to $400^{\circ} \mathrm{C}$ [5]. [8]. Thus, annealing experiments provide the possibility to distinguish between point defects or their clusters and defect cascades.

In this paper we present the results of the critical current and critical temperature measurements on two $\mathrm{YBaCuO}$ single crystals, which were irradiated with neutrons and protons respectively. After irradiation they were annealed at $100^{\circ} \mathrm{C}, 200^{\circ} \mathrm{C}$ and $300^{\circ} \mathrm{C}$ in air for $8 \mathrm{~h}$ each. The fluences for irradiation were chosen so that the maximum of the critical current is reached. After irradiation the samples exhibit comparable critical currents. The critical current at $10 \mathrm{~K}$ and IT is enhanced by a factor of 5 for the neutron irradiated sample and a factor of 9 for the proton irradiated sample. The enhancement of the critical current of the proton irradiated sample is mainly due to the creation of point defects or their clusters, whereas for the neutron irradiated sample it is caused by a combination of point defects or their clusters and defect cascades. As expected, annealing effects in the proton irradiated sample are stronger than in the neutron irradiated sample. The critical temperatures are decreased after irradiation with neutrons and protons by about $0.5 \mathrm{~K}$ and $1 \mathrm{~K}$ respectively and recover fully after annealing.

\section{EXPERIMENT}

$T_{c}$ measurements were carried out in a field of $10 e$ with Hilc, by cooling in zero field. Magnetization hysteresis measurements were carried out in a Quantum Design SQUID magnetometer in fields up to 5Tesla at temperatures of 10 and 70K.

Neutron irradiations were performed at the Missouri University Research Reactor (MURR) in the H1 position to a fluence of $2 \times 10^{17} \mathrm{n} / \mathrm{cm}^{2}(\mathrm{E}>0.1 \mathrm{MeV})$. Proton irradiation was carried out at room temperature in the TANDEM accelerator at Argonne National Laboratories. The crystal was irradiated to a fluence of $1 \times 10^{16} \mathrm{p} / \mathrm{cm}^{2}$ with $3.5 \mathrm{MeV}$ protons. The thickness of the crystal (30um) was less than the range of the protons at this energy ( $55 \mu \mathrm{m})$.

In the course of this experiment 6 neutron irradiated samples and 3 proton irradiated samples have been studied. The resuits are similar in all cases, the crystals shown here represent typical examples of the results.

\section{RESULTS}

The critical currents were calculated from the magnetization hysteresis measurements by using the anisotropic critical state model [9], [10]. In order to characterize the annealing results, the following definition for the reduction of the critical currents is used:

decrease $(\%)=\frac{\mathrm{J}_{\mathcal{C}}(\text { after irr. })-\mathrm{J}_{\mathrm{C}}(\text { after annealing })}{\mathrm{J}_{\mathrm{C}}(\text { after ir. })-\mathrm{J}_{\mathrm{C}}(\text { before irr. })} \times 100(1)$

Fig. 1 shows the results of the critical currents after irradiation and annealing for the neutron irradiated sample. 


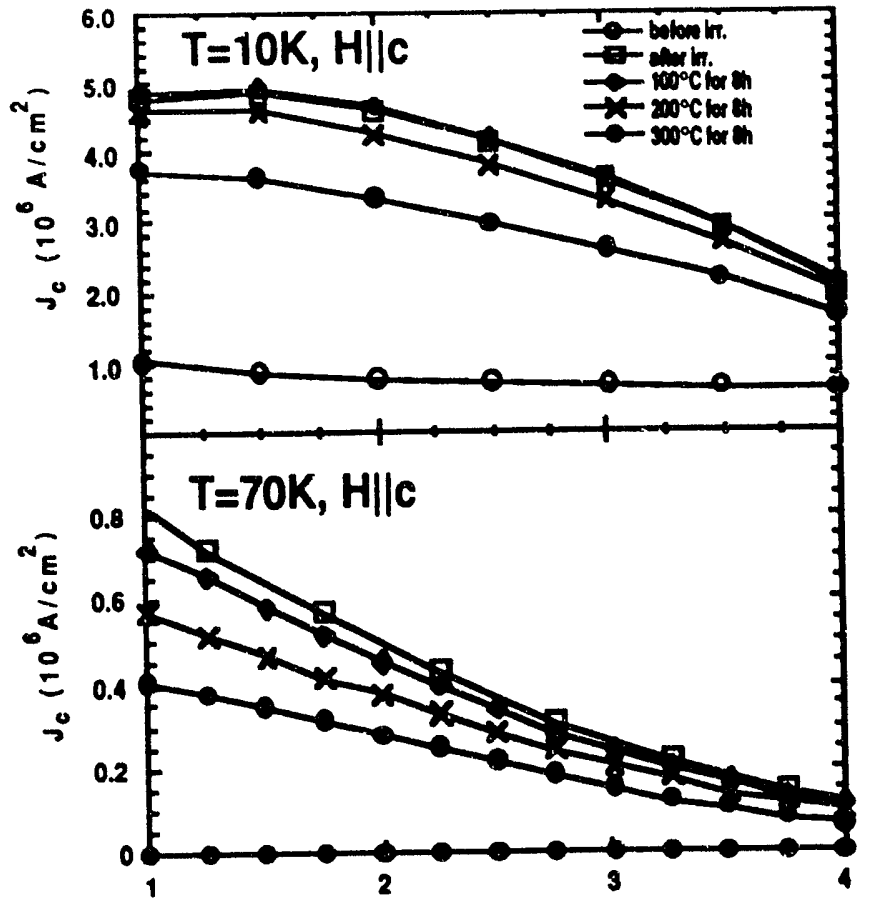

$H(T)$

Fig.1. Critical current density as a function of field for Hilc at 10K (top) and 70K (bottom) before neutron irradiation, after neutron irradiation and after annealing at $100^{\circ} \mathrm{C}, 200^{\circ} \mathrm{C}$ and $300^{\circ} \mathrm{C}$

Upon irradiation to a fluence of $2 \times 10^{17} \mathrm{n} / \mathrm{cm}^{2}$ we observe an increase in the critical current by a factor of 5 at 1 Tesla and $10 \mathrm{~K}$. The increase of the critical current at $70 \mathrm{~K}$ would be infinite, since essentially no hysteresis was observed before irradiation. After annealing at $100^{\circ} \mathrm{C}$ and $200^{\circ} \mathrm{C}$ we observe a slight decrease of the critical current at $10 \mathrm{~K}$ (using equation 1 , less than $10 \%$ at each step). After annealing at $300^{\circ} \mathrm{C}$ the critical current is reduced by ahout $30 \%$. At $70 \mathrm{~K}$, each annealing step leads to a decrease of the critical current. Annealing at $100^{\circ} \mathrm{C}$ has the smallest impact, leading to a decrease of about $10 \%$, annealing at $200^{\circ} \mathrm{C}$ and $300^{\circ} \mathrm{C}$ reduces the critical current by about $30 \%$ and $50 \%$ respectively.

Fig. 2 shows the results of annealing of the proton irradiated sample. Proton irradiation to a fluence of $1 \times 10^{16} \mathrm{p} / \mathrm{cin}^{2}$ leads to critical currents comparable to that of the neutron irradiated sample. A variation in critical currents by a factor of two is within the statistical variation of several crystals irradiated under identical conditions. The decrease of the critical current following annealing, however, seems now to be independent of measuring temperature. Each annealing step leads roughly to about the same decrease of the critical current of about $20 \%$. After the final annealing step the critical current is decreased by about $70 \%$ at $10 \mathrm{~K}$. A summary of the decrease of the critical currents as a function of annealing temperature at a field of $2 \mathrm{~T}$ is given in tablel.

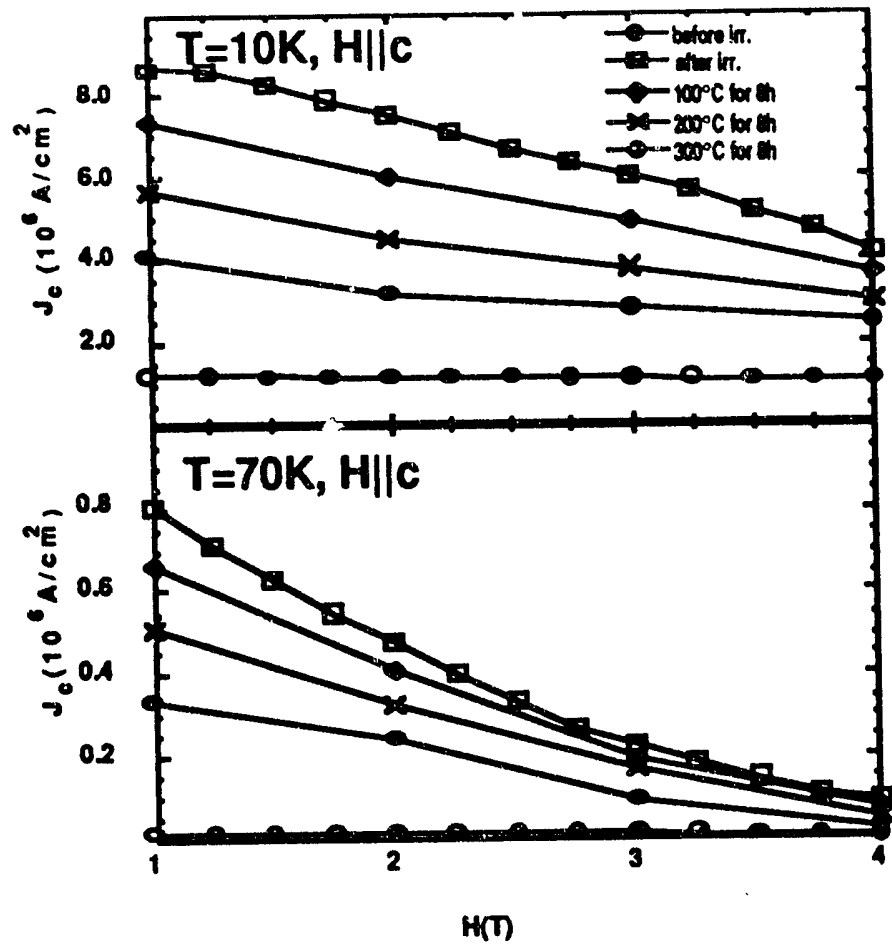

Fig.2. Critical current density as a function of field for Hilc at $10 \mathrm{~K}$ (top) and 70K (bottom) before proton irradiation, after proton irradiation and after annealing at $100^{\circ} \mathrm{C}, 200^{\circ} \mathrm{C}$ and $300^{\circ} \mathrm{C}$

Fig. 3 and Fig. 4 show the results of the measurements of the critical temperature of the neutron and proton irradiated sample respectively.

\begin{tabular}{|l|l|l|l|}
\hline Neutron irr. & $100^{\circ} \mathrm{C}$ & $200^{\circ} \mathrm{C}$ & $300^{\circ} \mathrm{C}$ \\
\hline $10 \mathrm{~K}$ & $0 \%$ & $9 \%$ & $33 \%$ \\
\hline $70 \mathrm{~K}$ & $9 \%$ & $34 \%$ & $52 \%$ \\
\hline Proton irr. & $100^{\circ} \mathrm{C}$ & $200^{\circ} \mathrm{C}$ & $300^{\circ} \mathrm{C}$ \\
\hline $10 \mathrm{~K}$ & $23 \%$ & $47 \%$ & $68 \%$ \\
\hline $70 \mathrm{~K}$ & $15 \%$ & $32 \%$ & $60 \%$ \\
\hline
\end{tabular}

Table.1 recovery of the critical current at a field of 2Tesla

Neutron irradiation reduces the critical temperature by about $0.5 \mathrm{~K}$. Each annealing step increases $T_{c}$, after annealing at $300^{\circ} \mathrm{C}$ the critical temperature is even slightly higher than before irradiation.

Proton irradiation leads to a reduction of the critical temperature by about $1 \mathrm{~K}$. Again it increases with each annealing step, after annealing at $300^{\circ} \mathrm{C}$ the critical temperature is again higher than before irradiation. 


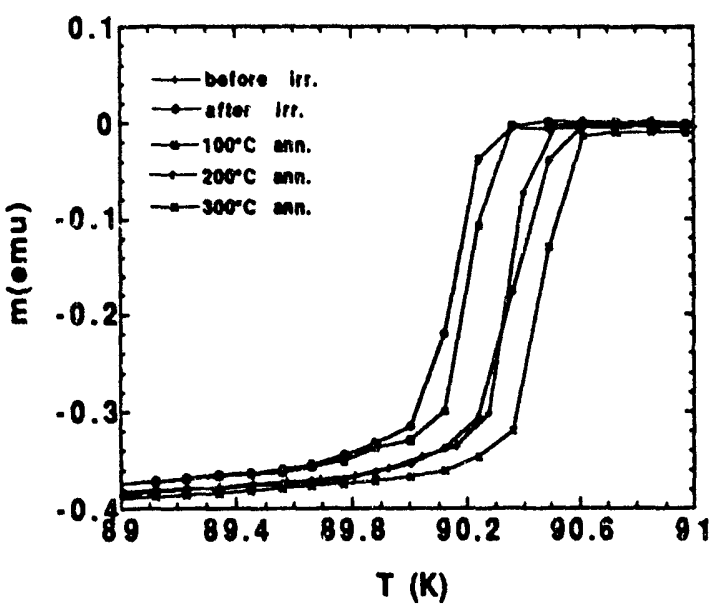

Fig.3. $\quad T_{c}$ before irradiation, after irradiation and annealing at $100^{\circ} \mathrm{C}, 200^{\circ} \mathrm{C}, 300^{\circ} \mathrm{C}$ of the neutron irradiated sample

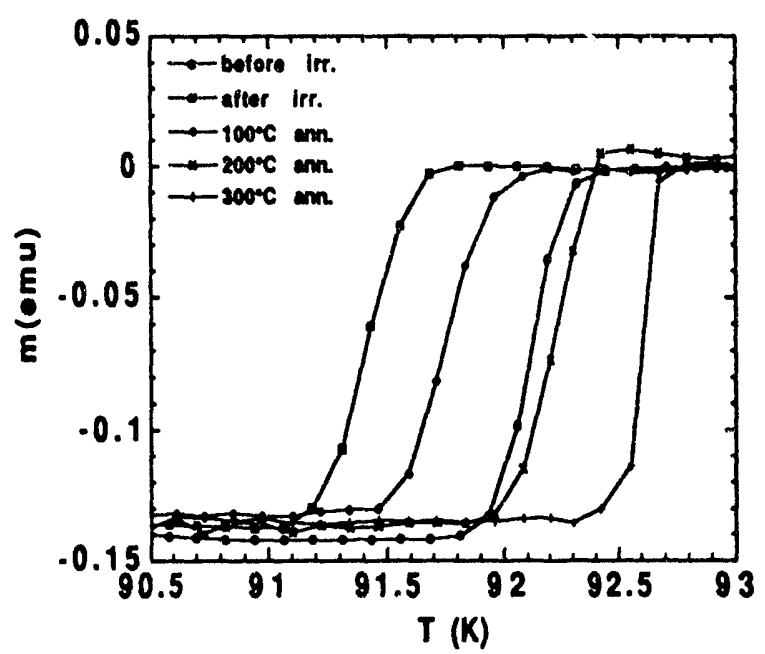

Fig.4. $\mathrm{T}_{\mathrm{c}}$ before irradiation, after irradiation and annealing at $100^{\circ} \mathrm{C}, 200^{\circ} \mathrm{C}, 300^{\circ} \mathrm{C}$ of the proton irradiated sample

\section{DISCUSSION}

Neutron irradiation creates defect cascades, point defects and clusters, whereas proton irradiation creates predominantly point defects and clusters. Both types of irradiation lead to an increase of the critical currents. Annealing the crystals at $100^{\circ} \mathrm{C}, 200^{\circ} \mathrm{C}$ and $300^{\circ} \mathrm{C}$ reduces the critical currents for both, the neutron and proton irradiated samples and leads to a recovery of $T_{c}$. It was shown in a previous publication [5], that annealing at these temperatures leaves the cascade defects unchanged, the decrease of the critical currents after annealing is therefore attributed to the removal of point defects or their clusters. The larger effect of annealing on the critical currents of the proton irradiated samples can be explained by the higher amount of point defects present after this type of irradiation. Since each annealing step leads to about the same decrease of the critical currents at 10 and $70 \mathrm{~K}$, these point defects or clusters are contributing to pinning by the same amount at each measuring temperature. About $70 \%$ of the critical current at $10 \mathrm{~K}$ and $60 \%$ of the critical current at $70 \mathrm{~K}$ is provided by point defects or their clusters. The pinning remaining after irradiation might be related to a more complex defect structure, which is described in detail in a recent publication [4].

In contrast, the critical currents of the neutron irradiated sample are more reduced at $70 \mathrm{~K}$ than at $10 \mathrm{~K}$. This suggests that in this case, the point defects or their clusters removed by annealing contribute more to pinning at higher measuring temperatures. This is surprising, since the defect cascades which are visible in 'TEM, are of a bigger size than the point defects or their clusters. The pinning left after annealing is then provided by the cascade defects which are very efficient pinning centers at $10 \mathrm{~K}$. The point defects or clusters are responsible for about $50 \%$ of the critical current at $70 \mathrm{~K}$, and only $30 \%$ at $10 \mathrm{~K}$.

Our data do not give any direct indication for the specific point defects or clusters responsible for pinning, however, based on former results on electron [3] as well as neutron irradiation [11], and taking the relatively low annealing temperatures into account, we believe that the point defects or clusters responsible for our annealing results are $\mathbf{O}$ displacements on the basal plane and Cu displacements on the $\mathrm{CuO}_{2}$ plane. The latter is believed to recover at annealing temperatures starting at $300^{\circ} \mathrm{C}$, and therefore responsible for the additional pinning in the neutron irradiated sample at 10 and $70 \mathrm{~K}$.

The reduction in $T_{C}$ is caused by oxygen disorder, which recovers during annealing at $100^{\circ} \mathrm{C}$ and $200^{\circ} \mathrm{C}$. These defects are not contributing significantly to pinning in the case of neutron irradiation. at $10 \mathrm{~K}$. It is interesting to note, that the critical temperature recovers fully after annealing, in both cases even slightly higher values than before irradiation are observed.

\section{SUMMARY}

After irradiating two $\mathrm{YBaCuO}$ single crystals with neutrons and protons at fluences where the maximum enhancement of the critical currents occurs, we observe comparable critical currents after irradiation. The depression of the critical temperature at these fluences is small, being about $0.5 \mathrm{~K}$ for the neutron irradiated and $1 \mathrm{~K}$ for the proton irradiated sample. Annealing experiments carried out at $100^{\circ} \mathrm{C}, 200^{\circ} \mathrm{C}$ and $300^{\circ} \mathrm{C}$ reveal that both types of irradiation create point defects or their small clusters, which contribute significantly to pinning. In the case of the proton irradiated sample these defects act as the main pinning centers being responsible for about $70 \%$ of the critical current after irradiation. Neutron irradiated samples are less susceptible to anncaling, due to an additional defect cascade structure, which is stable upon annealing. Point defects or clusters in this case 
contribute to $50 \%$ of the critical currents at $70 \mathrm{~K}$, and $30 \%$ of the criticai curent at $10 \mathrm{~K}$.

\section{ACKNOWLEDGEMENT}

We would like to thank J. Downey for the preparation of the crystals and J. Farmer as well as P. Baldo for irradiating the samples. This work was supported by the U. S. Department of Energy, Basic Energy Sciences-Materials Science under Contract No. W-31-109-ENG-38 (B. M. V., M. C. F., H. K. V., G. W. C., M. A. K.) and the National Science FoundationOffice of Science and Technology Center for Superconductivity, under Contract No. STC8809854 (U. W.)

\section{REFERENCES}

[1] A. Umezawa, G. W. Crabtree, J. Z. Liu, H. W. Weber, W. K. Kwok, L. H. Nunez, T. J. Moran, C. H. Sowers, "Enhanced critical magnetization currents due to fast neutron irradiation in single crystal $\mathrm{YBa}_{2} \mathrm{Cu}_{3} \mathrm{O}_{7-\delta "} \delta^{\prime}$. Phys. Rev. B., vol.36, pp.7151, November 1987.

[2] L. Cevale, A. D. Marwick, M. W. Mc Elfresh, T. K. Worthington, A. P. Malozemoff, F. H. Holtzberg, M. A. Kirk,"Defect Independence of the irreversibility line in proton-irradiated Y-Ba-Cu-O Crystals", Phys. Rev. Lett., vol. 65 , pp.1164, August 1990

[3] J. Giapintzakis, W. C. Lee, J. P. Rice, D. M. Ginsberg, I. M. Robertson, M. A. Kirk, R. Wheeler,"The production and identification of flux pinning defects by electron irradiation in YBa2 $\mathrm{Cu}_{3} \mathrm{O} 7-\delta$ single crystals", Phys. Rev. B, vol.45, pp.1677 [4] M. A. Kirk, "Structure and flux pinning properties of irradiation defects in $\mathrm{YBa}_{2} \mathrm{Cu}_{3} \mathrm{O}_{7-\delta^{\prime \prime}}$ in Critical Currents in High Tc Superconductors, Vienna, Austria, April 1992, to be published in Cryogenics

[5] B. M. Vlcek, M. C. Frischherz, S. Fleshler, U. Welp, J. Z. Liu, J. Downey, K. G. Vandervoort, G. W. Crabtree, M. A. Kirk, J. Giapintzakis, J. Farmer, "Flux pinning in $\mathrm{YBa}_{2} \mathrm{Cu}_{3} \mathrm{O}_{7-\delta}$ single crystals: Neutron irradiation and annealing", Phys. Rev. B. vol. 46, pp.6441, Sept. 1992

[6] M. Konczykowski, "Flux pinning enhancement after electron irradiation in $\mathrm{YBa}_{2} \mathrm{Cu}_{3} \mathrm{O}_{7-\delta^{\prime \prime}}$. Physica A., vol. 168, pp.291,

[7] J. Giapintzakis, M. A. Kirk, W. C. Lee, J. P. Rice, D. M. Ginsberg, I. M. Robertson, R. Wheeler, "Flux pinning induced by electron irradiation in $\mathrm{YBa}_{2} \mathrm{Cu}_{3} \mathrm{O}_{7}-\delta$ single crystals"to be published in Proc. Mat. Res. Soc. Symp. S, April 1992

[8] M. C. Frischherz, "Transmission electron microscopy studies of radiation induced defects in the high temperature superconductor $\mathrm{YBa}_{2} \mathrm{Cu}_{3} \mathrm{O}_{7}-\delta "$. Technical University of Vienna, Vienna, Austria, Ph. D. dissertation, 1992

[9] E. M. Gyorgy, R. B. van Dover, K. A. Jackson, L. F. Schncemeyer, J. V. Waszcak, "Anisotropic critical currents in $\mathrm{Ba}_{2} \mathrm{YCu}_{3} \mathrm{O}_{7}$ analyzed using an extended Bean model", Appl. Phys. Lett, vol. 55, pp..283, July 1989

[10] F. M. Sauerzopf, H. P. Wiesinger, H. W. Weber, "Anisotropic current flow and demagnetization corrections in the Bean model", Cryogenics, vol.30, pp. 650, July 1990

[11]K. E. Sickafus, J. O. Willis, P. J. Kung, W. B. Wilson, D. M. Parkin, M. P. Maley, F. W. Clinard, "Neutron irradiation induced flux pinning in Gd-doped $\mathrm{Y}_{1} \mathrm{Ba}_{2} \mathrm{Cu}_{3} \mathrm{O}_{7-x}$ and $\mathrm{Gd}_{1} \mathrm{Ba}_{2} \mathrm{Cu}_{3} \mathrm{O}_{7-x} x^{\prime \prime}$ submitted to Phys. Rev. B 

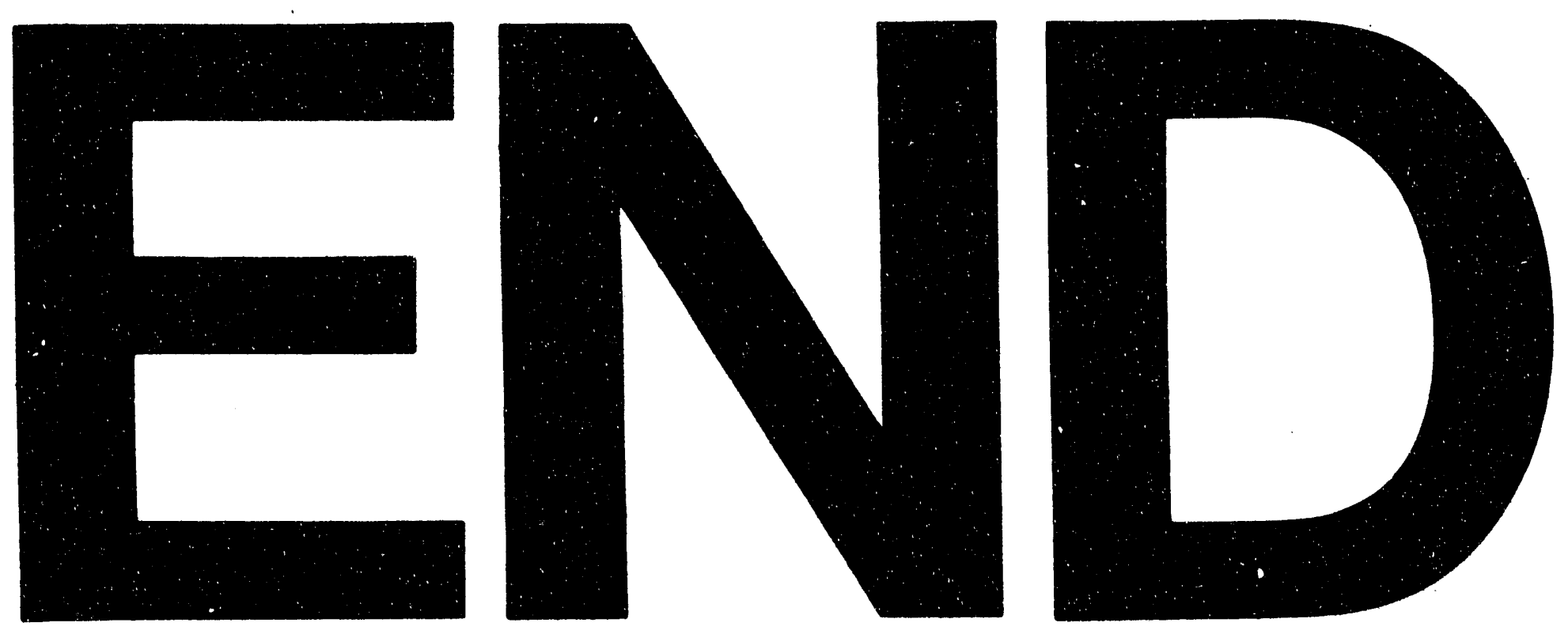

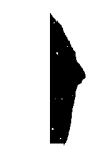
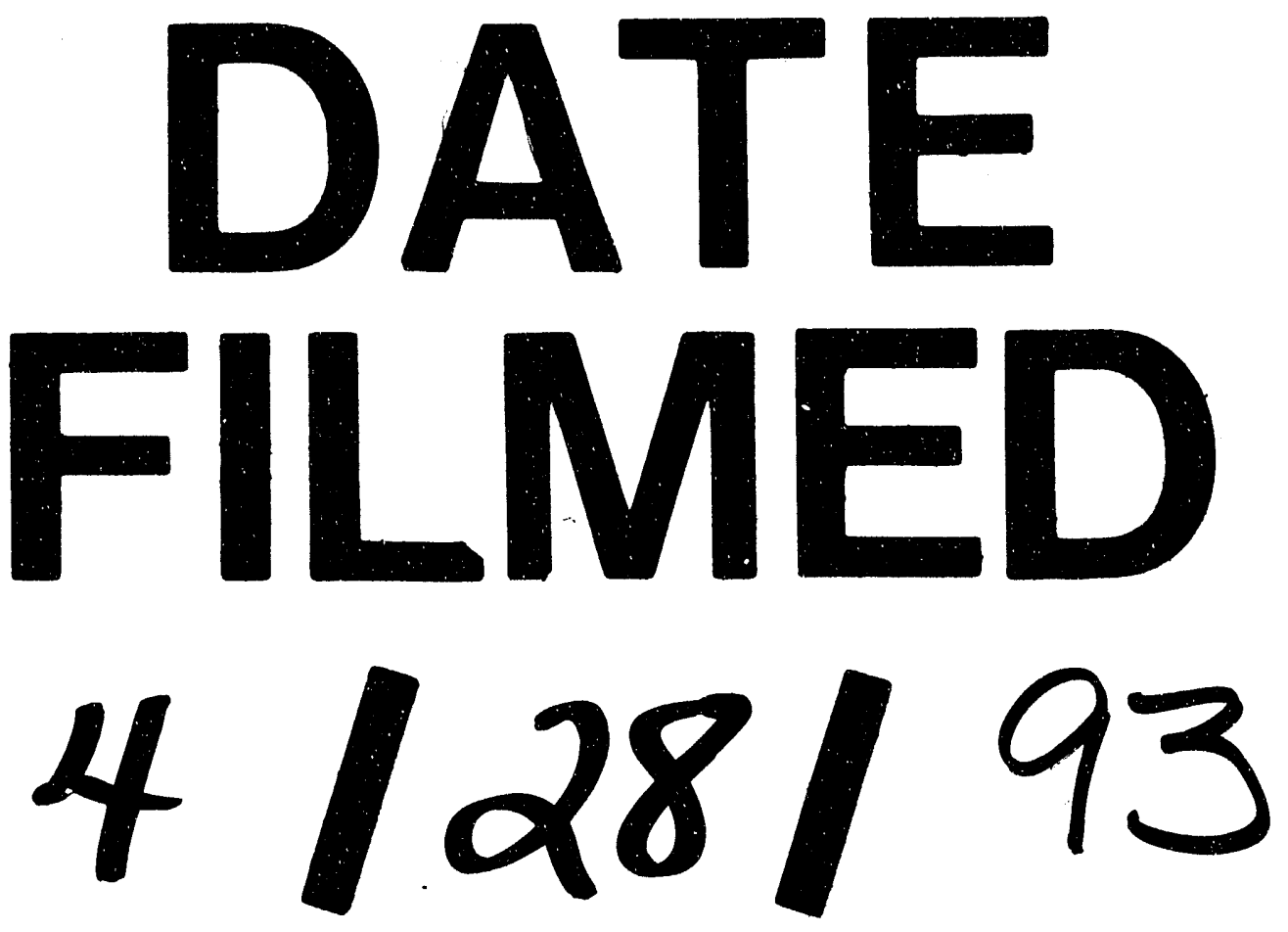
